Never and previous smokers had higher odds of remission at 1 year's follow-up compared to current smokers. In adjusted Cox regression analyses, baseline smoking was associated with shorter time to start of first bDMARD (Table 2).

Table 2. Impact of baseline smoking status on treatment outcomes

\begin{tabular}{lccc}
\hline & Comparison & Odds Ratio $(95 \% \mathrm{Cl})$ & $\mathrm{p}$ \\
\hline DAS28-remission 1 yr, yes vs. no* & Never vs. current smoker & $1.43(1.27 ; 1.62)$ & $<0.001$ \\
& Previous vs. current & $1.14(0.99 ; 1.30)$ & 0.07 \\
CDAl remission 1 yr, yes vs. no* & Never vs. current & $1.53(1.34 ; 1.75)$ & $<0.001$ \\
& Previous vs. current & $1.29(1.11 ; 1.50)$ & $<0.001$ \\
Start of bDMARD during & Comparison & Hazard Ratio $(95 \% \mathrm{Cl})$ & $\mathrm{p}$ \\
follow-up & Never vs current smoker & $0.85(0.76 ; 0.96)$ & 0.006 \\
& Previous vs. current & $1.05(0.93 ; 1.19)$ & 0.4 \\
\hline
\end{tabular}

*Logistic regression analyses (adjusted for gender and age)

${ }^{\star \star}$ Cox regression analyses (adjusted for gender and age)

Conclusion: In this observational study of $>8000$ patients with RA starting a first csDMARD, current smoking was associated with lower odds of achieving remission on methotrexate and higher chance of having started bMDARD compared to never smokers. Seropositivity may be an intermediate variable. Further analyses are planned to study impact of comorbidities and other confounding factors.

Acknowledgments : Thank you to all patients and departments who contribute to the DANBIO registry

Disclosure of Interests: : Bente Glintborg Grant/research support from: Grants from Pfizer, Biogen and Abbvie, Oliver Hendricks Grant/research support from: Pfizer, MSD, Ada Colic Consultant of: Advisory board Sanofi, Hanne Merete Lindegaard: None declared, Rabiah Ahmed: None declared, Anne Gitte Loft Grant/research support from: Novartis, Consultant of: AbbVie, MSD, Novartis, Pfizer and UCB, Speakers bureau: AbbVie, MSD, Novartis, Pfizer and UCB, Gina Kollerup Speakers bureau: Eli Lilly, Marlene Andersen: None declared, Jolanta Grydehøj: None declared, Johnny Raun: None declared, Toke Thorgrimsen: None declared, Kasper Mortensen: None declared, Line Uhrenholt Speakers bureau: Abbvie, Eli Lilly and Novartis (not related to the submitted work), Dorte Jensen: None declared, Iben Ruge Grant/research support from: Novo Nordisk Foundation, Maren Kalisz: None declared, Kamilla Danebod: None declared, Niels Lomborg: None declared, Niels Steen Krogh: None declared, Merete L. Hetland Grant/research support from: BMS, MSD, AbbVie, Roche, Novartis, Biogen and Pfizer, Consultant of: Eli Lilly, Speakers bureau: Orion Pharma, Biogen, Pfizer, CellTrion, Merck and Samsung Bioepis

DOI: 10.1136/annrheumdis-2020-eular.2344

\section{SAT0131 CARDIO- AND CEREBROVASCULAR RISK WITH CONVENTIONAL SYNTHETIC DISEASE-MODIFYING ANTIRHEUMATIC DRUGS (CSDMARDS) IN RHEUMATOID ARTHRITIS (RA): A REAL-WORLD COMPARATIVE ASSESSMENT}

A. Prats-Uribe ${ }^{1}$, B. Illingens ${ }^{2}$, D. Vizcaya ${ }^{3}$, J. Weaver ${ }^{4}$, E. Burn ${ }^{1,5}$, R. Sawant ${ }^{6}, K$. Marinier ${ }^{7}$, P. Ryan ${ }^{8}$, D. Prieto-Alhambra ${ }^{5,9}$ on behalf of European Health Data and Evidence Network (EHDEN) RA Research Group. ${ }^{1}$ University Of Oxford, Oxford, United Kingdom; ${ }^{2}$ Beth Israel Deaconess Medical Center, Department of Neurology, Harvard Medical School, Harvard, United States of America; ${ }^{3}$ Bayer Iberia, Barcelona, Spain: ${ }^{4}$ Janssen Research and Development, New Jersey, United Kingdom; ${ }^{5}$ Idiap Jordi Gol, Barcelona, Spain; ${ }^{6}$ Abbvie, Health Economics and Outcomes Research, North Chicago, United States of America; ${ }^{7}$ Servier, Suresnes, France; ${ }^{8}$ Janssen Research and Development, New Jersey, United States of America; ${ }^{9}$ University of Oxford, NDORMS, Oxford, United Kingdom

Background: RA is associated with an increased cardiovascular (CV) risk. csDMARDs are first-line treatments for RA and can mitigate this risk, but limited data exist on their $\mathrm{CV}$ effects. Previous trials have reported protective effects for methotrexate (MTX) and hydroxychloroquine (HCQ), but no similar data exist on sulfasalazine (SSZ) or leflunomide (LEF).

Objectives: To assess the comparative effect of csDMARDs on the risk of myocardial infarction (MI) and stroke in RA patients

Methods: Data from 6 claims/electronic health records databases across Germany, US, and UK, all mapped to the Observational Medical Outcomes Partnership (OMOP) common data model. A cohort study was conducted including patients $\geq 18$ years old, with first RA diagnosis in 2005-2019, initiating csDMARD monotherapy with MTX, HCQ, SSZ, or LEF. Those with a prior diagnosis of other inflammatory arthritis or $<1$ year prior follow-up were excluded. Patients were followed until first outcome, death, loss of or 5 years follow-up. Propensity score stratification was used, and hazard ratios (HR) estimated for HCQ, SSZ and LEF compared to MTX in each dataset using Cox regression. HR were calibrated (cHR) for residual confounding using negative control outcomes. Estimates were pooled where $I^{2}$ for heterogeneity $<0.4$. Intention to treat and an on treatment analyses are reported.

Results: 145,248 patients were included (MTX: 73,996, HCQ: 49,752, SSZ: 12,256, LEF: 9,244). Pooled rates of MI and stroke for MTX were 7.64 and 10.26 per 1,000 person years respectively. Detailed estimate $\mathrm{cHRs}$ are shown in Figure 1 for the intention to treat analysis. MI risk with SSZ and LEF was comparable to MTX. Risk of stroke was similar between LEF and MTX, but reduced for $\mathrm{HCQ}$ and SSZ compared to $\mathrm{MTX}$, with pooled $\mathrm{cHR}(95 \% \mathrm{Cl}) 0.86$ ( 0.78 to 0.95 ) and 0.71 ( 0.52 to 0.98 ) for $\mathrm{HCQ}$ and SSZ respectively. Similar results were found for "on treatment" analyses.
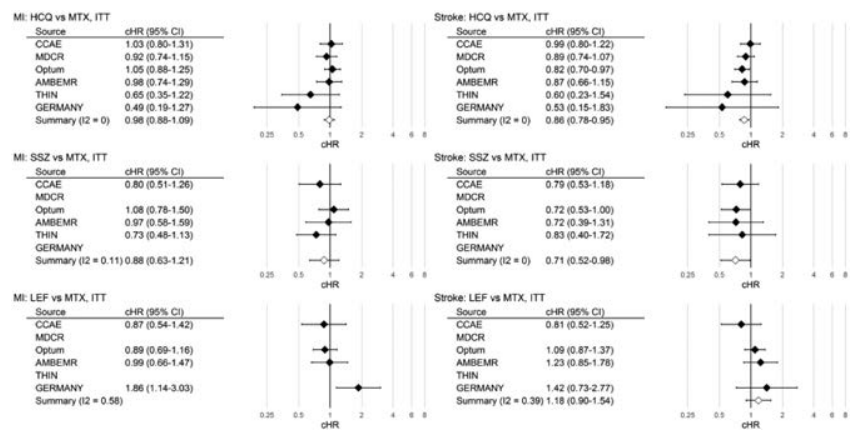

Figure 1. Calibrated hazard ratios (cHRs) for MI and stroke

Conclusion: Overall, all four csDMARDs had similar effects on MI risk. HCQ and SSZ use were associated with a decreased risk of stroke compared to MTX. The observed differences may be attributable to differential effects on the atherosclerotic process, differential disease control, or both.

Database estimates not reported where adequate covariate balance not attained. Meta-analysis results not reported where I2>0.4. MEDICARE did not pass diagnostics for SSZ and LEF analyses. cHR: calibrated Hazard Ratio; Cl: Confidence Interval; MTX: Methotrexate; HCQ: Hydroxychloroquine; SSZ: sulphasalazine; LEF: Leflunomide; THIN: The Health Improvement Network (UK); Optum: Optum de-identified Clinformatics Datamart (US); MDCR: Medicare (US); GERMANY: IQVIA Disease Analyzer EMR (Germany); CCAE: IBM MarketScan Commercial Claims and Encounters (US); AMBEMR: IQVIA Ambulatory EMR (US)

Database estimates not reported where adequate covariate balance not attained. Meta-analysis results not reported where I2>0.4. MEDICARE did not pass diagnostics for SSZ and LEF analyses. cHR: calibrated Hazard Ratio; $\mathrm{Cl}$ : Confidence Interval; MTX: Methotrexate; HCQ: Hydroxychloroquine; SSZ: sulphasalazine; LEF: Leflunomide; THIN: The Health Improvement Network (UK); Optum: Optum de-identified Clinformatics Datamart (US); MDCR: Medicare (US); GERMANY: IQVIA Disease Analyzer EMR (Germany); CCAE: IBM MarketScan Commercial Claims and Encounters (US); AMBEMR: IQVIA Ambulatory EMR (US)

Disclosure of Interests: : Albert Prats-Uribe: None declared, Ben Illingens: None declared, David Vizcaya Employee of: Bayer, James Weaver Shareholder of: J\&J Shares, Grant/research support from: Full-time employment salary from Janssen, Consultant of: Janssen employee, Employee of: Janssen, Paid instructor for: Janssen employee, have instructed at conferences, Speakers bureau: Janssen employee, have spoken at conferences, Edward Burn: None declared, Ruta Sawant Shareholder of: AbbVie, Employee of: AbbVie, Karine Marinier Employee of: Servier, Patrick Ryan: None declared Daniel Prieto-Alhambra Grant/research support from: Professor Prieto-Alhambra has received research Grants from AMGEN, UCB Biopharma and Les Laboratoires Servier, Consultant of: DPA's department has received fees for consultancy services from UCB Biopharma, Speakers bureau: DPA's department has received fees for speaker and advisory board membership services from Amgen

DOI: 10.1136/annrheumdis-2020-eular.3463 